\title{
PerCursos
}

\section{Jovens na cena metropolitana de Florianópolis: encantos e desencantos na 'Ilha da Magia'}

\section{Resumo}

Este estudo apresenta os resultados de uma pesquisa desenvolvida com jovens egressos de cursos técnicos do eixo turismo, hospitalidade e lazer. Trata-se de uma pesquisa qualitativa (MINAYO, 2014), desenvolvida entre 2016 e 2017 com egressos formados há mais de três anos e moradores da região metropolitana de Florianópolis. $\mathrm{O}$ artigo problematiza as dificuldades de inserção profissional da juventude, as lutas travadas na ocupação da cidade $e$ as estratégias para sobrevivência em tempos de desregulamentação das leis trabalhistas e direitos sociais. A pesquisa demonstra a incorporação dos discursos do mercado pelos jovens egressos no que diz respeito à qualificação profissional e à "opção" pelo empreendedorismo e uberização como saída individual para uma crise que é estrutural do capitalismo.

Palavras-chave: Juventude. Território. Plano Diretor. Trabalho. Uberização.

\author{
Valdeci Reis \\ Doutorando em Educação e \\ Mestre em Educação pela \\ Universidade do Estado de Santa \\ Catarina - UDESC. Técnico em \\ Educação do Instituto Federal de \\ Santa Catarina - IFSC. \\ Brasil \\ valdeci.reis@ifsc.edu.br

\section{Meimilany Gelsleichter} \\ Mestra em Educação pela \\ Universidade do Estado de Santa \\ Catarina - UDESC. Pedagoga do \\ Instituto Federal de Santa \\ Catarina - IFSC. \\ Brasil \\ meimilany@ifsc.edu.br
}

\section{Para citar este artigo:}

REIS, Valdeci; GELSLEICHTER, Meimilany. Jovens na cena metropolitana de Florianópolis: encantos e desencantos na 'Illha da Magia'. Revista PerCursos, Florianópolis, v. 20, n.42, p. 253 - 279, jan./abr. 2019.

DOI: $10.5965 / 1984724620422019253$

http://dx.doi.org/10.5965/1984724620422019253 


\title{
Young people in the metropolitan scene of Florianópolis: delights and disappointments in the 'Magic Island'
}

\begin{abstract}
This study presents the results of a research developed with youngsters who attended technical education courses in the areas of tourism, hospitality and leisure. It is a qualitative research (MINAYO, 2014), developed between 2016 and 2017 with students who completed the course more than three years ago and residents of the metropolitan region of Florianópolis, SC, Brazil. The article discusses the difficulties of youth employment, the struggles of the occupation of the city and strategies for survival in times of deregulation of labor laws and social rights. The research demonstrates the incorporation of the market discourses by young people regarding professional qualification and the "option" for entrepreneurship and the called "uberization" phenomenon as an individual solution for a crisis that is structured by capitalism.
\end{abstract}

Keywords: Youth. Territory. Plan Director. Work. Uberization. 


\section{Introdução}

Nas últimas décadas, a academia tem promovido vários debates em torno da temática juventude: inserção no mundo do trabalho, sociabilidade e interação nos mais variados territórios: sexualidade, índices alarmantes de homicídios, consumo de álcool e drogas ilícitas, acesso à informação e ao conhecimento, uso e apropriação das tecnologias digitais. Essas são algumas das questões que desafiam a autonomia e a convivência dos jovens na cidade urbana (BORELI, ROCHA e OLIVEIRA, 2013; REIS, 2016).

No Brasil, a década de 1990 foi marcada pelo lançamento de um novo quadro geral de oferta educacional ${ }^{1}$ que expressa as novas formas e condições de formação humana em andamento, envolvendo os variados setores de ação governamental voltados a algum tipo de “projeto social” que, segundo Rummert, Algebaile e Ventura (2013), dirigem-se aos mais diferentes propósitos (financiamento de ações regulares, ajustes institucionais, ampliação ou reforma infraestrutural, formação funcional, indução de políticas, entre outras). A partir disso, podemos destacar os programas dirigidos à formação de crianças, adolescentes, jovens e adultos considerados pobres, ou seja, aqueles expropriados do próprio direito à vida, num patamar mínimo de dignidade.

A multiplicação de ofertas dessa natureza criou um clima eufórico com relação ao acesso à educação, porém, quando as ofertas são observadas de forma crítica e calcadas na materialidade concreta, constata-se um falseamento da realidade ou, ainda, uma 'inclusão excludente', conforme apontou Kuenzer (2010), visto que esses cursos oferecem uma resposta imediata do Estado às emergentes necessidades do mercado e referendam o discurso da 'oportunização' de acesso à escola e ao conhecimento. Assim,

\footnotetext{
${ }^{1}$ Destacam-se aqui os programas criados pelo governo federal, ligados à Presidência da República ou a ministérios, envolvendo: cursos de alfabetização, como os realizados pelos Programas Alfabetização Solidária e Brasil Alfabetizado; de educação geral e formação profissional inicial, vinculados à concessão de renda mínima por período determinado, como o Agente Jovem e o Programa Nacional de Inclusão de Jovens (PROJOVEM); de formação geral e profissional sem vínculo com renda mínima, como o Programa Nacional de Integração da Educação Profissional com a Educação Básica na Modalidade de Educação de Jovens e Adultos (PROEJA); de ampliação da escolarização de profissionais de áreas específicas, como o Projeto de Profissionalização dos Trabalhadores da Área de Enfermagem (PROFAE) e o Programa Nacional de Educação na Reforma Agrária (PRONERA); além dos novos sistemas de exames com certificação - Exame Nacional de Certificação de Competências de Jovens e Adultos (ENCCEJA) e Rede Nacional de Certificação Profissional e Formação Inicial e Continuada (Rede CERTIFIC) (RUMMERT, ALGEBAILE \& VENTURA, 2013, p. 727-729).
} 
cada vez mais não se consolidam as ações destinadas à elevação igualitária do nível educacional da classe trabalhadora em sua totalidade e reafirma-se a dualidade educacional fundante do modo de produção capitalista (RUMMERT, ALGEBAILE \& VENTURA, 2013).

Um dos debates mais intensos travados na sociologia contemporânea tem sido a tentativa de responder à seguinte pergunta: em que momento o indivíduo deixa de ser jovem e atinge a vida adulta? Certamente, não se trata de uma questão fácil de ser dirimida, tendo em vista que, para além dos aspectos biológicos, o conceito de juventude também dialoga com os fatos históricos, culturais e políticos de cada sociedade.

A partir da aprovação do Estatuto da Juventude², o conjunto de políticas públicas implementadas pelos ministérios nos últimos quatro anos - criação do Conselho Nacional da Juventude, Secretaria Nacional da Juventude, Programa Nacional de Inclusão de Jovens - passou a definir como jovens indivíduos com idade até 29 anos. A partir da leitura dos decretos e orientações do poder executivo federal, pode-se problematizar o que vem acontecendo nas cidades brasileiras que levou nossos governantes a alargar o conceito de juventude.

Carrano (2011) aponta que as dificuldades de inserção profissional dos jovens, o que não é uma especificidade do Brasil, estão entre as questões centrais de um movimento global de estender a 'juvenialização'. Para o autor, esse é um dos fatores que contribuiu para o alargamento do conceito de juventude na América Latina (15 a 29 anos) e na Europa (15 a 34 anos).

De fato, várias pesquisas têm identificado um prolongamento da fase juvenil (DAYRELL 2003, 2005, 2007). Nos últimos anos, estudos identificaram que os jovens ficam mais tempo na casa dos pais, o percurso escolar foi estendido e, consequentemente, a inserção no mundo do trabalho acaba ocorrendo mais tarde.

\footnotetext{
${ }^{2}$ Lei n. 12.852, de 5 de agosto de 2013. Institui o Estatuto da Juventude e dispõe sobre os direitos dos jovens, os princípios e diretrizes das políticas públicas de juventude e o Sistema Nacional de Juventude SINAJUVE. Disponível em: <http://www.planalto.gov.br/ccivil_03/_Ato2011-2014/2013/Lei/L12852.htm>. Acesso em: 14 mar. 2018.
} 
Ao observar as políticas públicas colocadas em curso pelo governo brasileiro no período entre 2003 e 2016, é possível identificar uma iniciativa que priorizou a qualificação profissional como fator indispensável para que o jovem pudesse adentrar o mercado de trabalho. Todavia, não houve uma mudança estrutural nos setores produtivos da economia brasileira que pudesse absorver esse jovem qualificado. Com a expansão de matrículas nas universidades e escolas profissionalizantes, ocorreu o fenômeno que Bourdieu (1992) denomina como a 'inflação do diploma'.

O presente artigo analisa as narrativas de jovens egressos de cursos técnicos de um Campus do Instituto Federal especializado em qualificar trabalhadores no eixo turismo, hospitalidade, lazer e produção de alimentos, localizado no município de Florianópolis, estado de Santa Catarina ${ }^{3}$. Considerando o cenário da atual crise no mundo do trabalho, flexibilização das leis trabalhistas, aumento dos conflitos sociais no espaço urbano, a pesquisa procurou desvendar as trajetórias profissionais dos jovens que concluíram cursos técnicos profissionalizantes na área de Gastronomia e Indústria de Alimentos.

Um estudo realizado por Reis, Gelsleichter e Alves (2017) constatou que na capital do estado de Santa Catarina a oferta de serviços no ramo do turismo é a segunda principal fonte de arrecadação de impostos. Cotidianamente, os meios de comunicação de massa amplificam o discurso da classe patronal - FECOMERCIO ${ }^{4}, \mathrm{CDL}^{5}$ - de que no município sobram oportunidades de empregos; todavia, falta mão de obra qualificada.

A partir das narrativas juvenis, buscamos refletir os sentidos que os próprios jovens atribuem às suas trajetórias de inserção profissional após terem participado de um curso profissionalizante no Instituto Federal de Santa Catarina. Trata-se de um estudo qualitativo realizado com jovens (egressos de até 29 anos) dos cursos técnicos de Gastronomia, Panificação e Confeitaria. Para a referida pesquisa, foram selecionados educandos que concluíram a sua formação no período entre 2012 e 2013. No recorte

\footnotetext{
3 Trata-se de uma pesquisa financiada pela Pró-Reitoria de Pesquisa e Inovação Tecnológica do Instituto Federal de Santa Catarina. A pesquisa contou com a colaboração da bolsista de pesquisa Maristela Borges. ${ }^{4}$ Federação do Comércio de Bens, Serviços e Turismo de Santa Catarina.

${ }^{5}$ Câmara de Dirigentes Lojistas de Florianópolis.
} 
temporal informado, o Campus Florianópolis-Continente do IFSC ${ }^{6}$ formou 31 Técnicos em Panificação e Confeitaria (dos quais seis eram jovens), e 41 Técnicos em Gastronomia (dos quais 18 eram jovens). Para o referido estudo, foram selecionados 16 jovens egressos.

\section{As disputas em torno da 'Illha da Magia' e as novas dinâmicas do capitalismo globalizado}

Um dos conflitos mais acentuados nas últimas três décadas na cidade de Florianópolis tem sido a disputa pelo direito à habitação. Com o fortalecimento da especulação imobiliária elevando os preços dos imóveis e aluguéis, junto à intensificação dos movimentos migratórios, pessoas vêm de outros estados para atuarem, geralmente, no setor de serviços. Nesse sentido, residir no município tem sido um grande desafio, especialmente para os imigrantes que vêm busca da tão propagada 'qualidade de vida'.

Reis, Gelsleichter e Alves (2017) constataram que, na última década, várias comunidades em situação de vulnerabilidade social surgiram em áreas de preservação ambiental: Favela do Siri, localizada nas dunas da Praia dos Ingleses; Morro do Mosquito, comunidade que se formou no entorno de uma área verde no norte da ilha; Favela Papaquara, erguida em uma área de mangue próxima ao Balneário de Canasvieiras.

Esse movimento de ocupação nas extremidades da ilha de Santa Catarina ocorre após o maciço do Morro da Cruz, área central da cidade, estar quase que totalmente ocupado por imigrantes que, ao chegarem ao município, não tendo um local para morar, subiram a encosta e construíram um abrigo. Estudo realizado por Caruso (2012) demonstrou que, em três décadas de ocupação, mais de $80 \%$ da vegetação do Morro da Cruz foi destruída.

Quando esses imigrantes chegam à cidade, normalmente nos meses de novembro ou dezembro, rapidamente são absorvidos pelo setor de serviços (hotéis, bares e restaurantes). Encerrada a temporada de verão (abril), esses trabalhadores são dispensados. Como grande parte dessas pessoas decide permanecer na ilha em busca de

\footnotetext{
${ }^{6}$ Instituto Federal de Santa Catarina.
} 
outra oportunidade de trabalho, em função da perda da moradia que antes era proporcionada pelo patrão, resta ao indivíduo desempregado a ocupação de 'guetos' nas regiões periféricas do município.

As lutas em torno da moradia na cidade de Florianópolis nos remetem à década de 50 do século XX. Uma sistematização elaborada por Pereira (2017) aponta que na referida década foi elaborado o primeiro plano diretor, que teve pouca participação da comunidade. Já em 1976, o poder executivo colocou em curso o segundo plano diretor, este com um viés fortemente desenvolvimentista, algo apontado na época como necessário para fortalecer a economia da capital que até então era baseada na pesca e na oferta de alguns serviços públicos.

Uma terceira reformulação do plano diretor da cidade ocorreu em 1997. Embora, em linhas gerais, se possa afirmar que essa edição ratificou os princípios desenvolvimentistas do plano de 1976, nessa versão houve uma maior participação da população, que expressou os aspectos negativos ao crescimento urbano que vinha ocorrendo sem o devido planejamento.

Uma nova revisão do plano foi colocada em curso pela Prefeitura Municipal em 2006, por força lei 10.257/2001, que instituiu o Estatuto da Cidade e previa a participação popular no planejamento urbano. Nesse período, já haviam se consolidado na ilha de Santa Catarina movimentos sociais organizados críticos ao modelo desenvolvimentista “baseado na construção civil e no turismo" (PEREIRA, 2017, p. 244). Estudos que se debruçaram a analisar esse período apontam que foi um processo marcado por conflitos e resistências, mas esse movimento impulsionou debates de alto nível sobre o direito à cidade (PEREIRA, 2015; SAMPAIO, 2016).

Mais de uma década se passou e a nova versão do plano diretor ainda não foi totalmente concluída. O embate acirrado entre os movimentos sociais organizados versus prefeitura e representantes do sindicato da construção civil levou à judicialização de inúmeras etapas do processo. 
Não obstante todos os problemas observados no processo de Florianópolis, percebemos que algumas comunidades conseguiram fazer valer suas demandas graças à tradição participativa (ou densidade participativa) apresentada, que se manifestou pelo exercício de uma forte territorialidade. Foi o caso da Comunidade do Campeche, que possui uma demanda histórica pela prevalência da baixa densidade e do gabarito de dois pavimentos em todo o seu distrito. Num município onde a indústria da construção civil apresenta uma força muito grande na definição dos índices urbanísticos, sempre na busca de maiores densidades e gabaritos, esse aspecto é muito relevante. A garantia dessas demandas também foi observada em outras comunidades que tiveram importante participação no processo, como o Distrito de Santo Antônio de Lisboa ou o bairro de Coqueiros, que defenderam, igualmente, a limitação de índices construtivos em seus territórios. (PEREIRA, 2017, p. 248)

Para o autor, uma efetiva participação social e democrática no processo de elaboração de um plano diretor municipal é possível quando são respeitados quatro elementos fundamentais: 1) vontade política; 2) tradição participativa da comunidade; 3) condições institucionais e administrativas para que o processo aconteça; 4) adesão e participação dos técnicos urbanistas.

No caso específico de Florianópolis, o pesquisador destaca que a participação das comunidades distritais, bem como sua articulação com universidade e movimentos sociais, foi essencial para subverter as intenções do poder público em acelerar o processo de votação e restringir o número de representantes distritais na composição do Núcleo Gestor Municipal.

A partir do movimento de resistência liderado pelas comunidades do Campeche, Morro das Pedras, Lagoa da Conceição, Santo Antônio de Lisboa, Sambaqui e Coqueiros e a pouca participação das comunidades de Canasvieiras, Ingleses, Rio Vermelho, Jurerê e Cachoeira do Bom Jesus -, podemos concluir que, na ausência da participação comunitária organizada abre-se o espaço para o capital imobiliário ditar e impor as regras do mercado financeiro no planejamento da cidade.

A cidade de Florianópolis/SC, mesmo sendo uma pequena ilha, não se encontra isolada e incólume às ressonâncias da economia globalizada. Seus arranjos produtivos recebem as influências provocadas pelas novas dinâmicas do capitalismo, que afetam a 
cidade em vários aspectos da sua vida cotidiana. A "Capital Turística do MERCOSUL7”, assim denominada pelos parlamentares da cidade em 1993, também sofreu alterações sociais e políticas em função dos investimentos efetuados no setor turístico, especialmente depois dos anos 1980, que passam a dar a tônica da necessidade de formação de mão de obra qualificada para o setor.

No caso específico da formação voltada para o turismo, Lins, em pesquisa efetuada na Barra da Lagoa em Florianópolis, aponta:

Percebe-se que trabalhar no turismo tem significado principalmente atuar como garçom, cozinheiro ou ajudante de cozinheiro, vigia, faxineira e camareira, entre outras ocupações do gênero (...) observou-se que mais de $2 / 3$ da mão-de-obra ocupada vinculava-se a tarefas outras que as de gerência/administração. Essa participação era elevada notadamente nos serviços de alimentação, atingindo $85 \%$ do total. (LINS, 1993, p. 102)

Nesse sentido, estudos de migração interna também sinalizam (BARBOSA, 2000) que ocupações de âmbito doméstico, condomínios/edifícios, no ramo de serviços, especificamente em redes de hotéis e restaurantes, são as mais significativas incorporadoras de migrantes e imigrantes sem qualificação, que visam à inserção no mercado de trabalho urbano. Por isso, a necessidade de formação dos trabalhadores para o trabalho simples na periferia do capital, ou ainda em países de primeiro mundo, parece não se alterar. Em Florianópolis, "a utilização de pessoas do local para tarefas que não requerem nenhum treinamento específico caracteriza igualmente outras localidades alcançadas pelo turismo, como Lagoinha, no Norte da Ilha de Santa Catarina" (BECK, 1979, p. 74). Em outro estudo, acrescenta: “Nestas, observa-se igualmente o particular

\footnotetext{
7 "Estudos mercadológicos de turismo receptivos desenvolvidos pelo Instituto Embratur, ainda neste ano de 1993, identificaram que, dentre os treze sítios turísticos brasileiros mais visitados por fluxos estrangeiros, a cidade de Florianópolis - capital do estado de Santa Catarina - aparece em SEGUNDO LUGAR como destino turístico preferencial. Esta posição, contudo, não é fruto de mero acaso. Ao contrário, a par de sua privilegiada localização geográfica, suas especificidades naturais e sua cultura, Florianópolis tem se destacado pelo expressivo e crescente aporte de investimentos, tanto da iniciativa privada quanto dos órgãos públicos (...). Por tudo isso, e pelas excelentes perspectivas que se podem antever com o aumento crescente do fluxo de turistas ao estado, a Assembleia Legislativa do Estado de Santa Catarina, por seu Presidente, propõe que a cidade de Florianópolis seja considerada a CAPITAL TURÍSTICA DO MERCOSUL". (RANZOLIN, Ivan. Ata da Assembleia Legislativa do Estado de Santa Catarina. Florianópolis, 11 de novembro de 1993 [grifo nosso]).
} 


\section{envolvimento de mulheres em tarefas de limpeza e manutenção doméstica, tanto em} hotéis como em casas de veraneio (BECK, 1983, p. 43, grifo nosso).

A polivalência ${ }^{8}$, fruto da nova morfologia do trabalho9 ${ }^{9}$, é outra característica do setor de serviços. No ramo do turismo, especialmente nos pequenos empreendimentos, é comum que o trabalhador desenvolva concomitantemente o trabalho de camareira, auxiliar de cozinha, garçonete, atendente de piscina, jardinagem etc.

Lins (1993), quando pesquisou as alterações provocadas pelo turismo na Barra da Lagoa desde os anos 1980, constatou que esse eixo econômico opera como um "lubrificante" da engrenagem que produz as transformações, ampliando e acelerando o processo de abandono das atividades tradicionais. Ao permitir novas ocupações na própria localidade, reduz a indecisão sobre largar a pesca, por exemplo, permitindo ao trabalhador a conciliação entre várias atividades. Essa possibilidade reforça sua identidade polivalente, que se constitui por sua plasticidade, adaptabilidade e capacidade de executar tarefas de naturezas distintas, tornando-o mais facilmente adaptável e explorável. Além disso, possibilita que os nativos trabalhem próximos de suas casas e agreguem o turismo ao horizonte de suas atividades. Em suas palavras:

Quase $2 / 3$ dos efetivos engajados nos serviços de hospedagem e alimentação pesquisados era originário da própria Barra da Lagoa, uma participação que aumentava para $86 \%$ no caso da hospedagem. Deste modo, ainda que corresponda a somente um elemento do processo de transformação ocupacional, o turismo mostra-se, não obstante, um significativo tributário deste, posto que o torna mais veloz e amplo. (LINS, 1993, p. 102)

\footnotetext{
${ }^{8}$ Que se opõe ao conceito Politecnia. O conceito de "educação politécnica" foi esboçado inicialmente por Karl Marx, em meados do século XIX. Em outras palavras, “educação politécnica” pode ser vista como sinônimo de concepção marxista de educação (FRIGOTTO, CIAVATTA \& RAMOS, 2005).

9"Nova morfologia que, no Brasil, compreende desde o operariado industrial e rural, até os assalariados de serviços, os novos contingentes de homens e mulheres terceirizados, subcontratados, temporários que se ampliam. Nova morfologia que presencia a ampliação de novos proletários do mundo industrial, de serviços e da agroindústria, de que são exemplos as trabalhadoras de telemarketing e call center, das tecnologias de informação e comunicação que se desenvolvem na era digital, além dos digitalizadores que laboram nos bancos, dos assalariados do fastfood, dos trabalhadores jovens dos hipermercados, dos motoboys que morrem nas ruas e avenidas, usando suas motocicletas para transportar mercadorias etc. $\mathrm{E}$ essas distintas modalidades de trabalho vêm desempenhando um papel de destaque não só na agilização da circulação de informações, vital para a reprodução do capital, como também no desencadeamento de novas lutas sociais e sindicais" (ANTUNES, 2014, p. 50).
} 
Embora o turismo de Florianópolis contrate pessoas com baixa qualificação e pague salários não muito atrativos, o discurso da qualificação atravessa o setor, justificando a existência de cursos de formação profissional na área. Ainda que subserviente ao capital, existe no imaginário social uma visão redentora de escola, bastante fundada na Teoria do Capital Humano, que projeta sobre os indivíduos expectativas com relação à qualificação profissional.

Por outro lado, a relação direta entre escolarização e ascensão profissional e até mesmo social, outrora sustentada por Schultz (1967), quando contrastada com a materialidade, não se sustenta como regra, pois a qualificação profissional, no atual estágio de desenvolvimento do capitalismo, tem servido muito mais como credencial para a disputa de vagas no mercado de trabalho, pouco implicando a promoção de uma formação mais ampla do trabalhador.

A racionalização dos processos produtivos tem implicado uma extraordinária economia de trabalho vivo, elevando brutalmente a composição orgânica do capital; resultado direto na sociedade capitalista: o crescimento exponencial da força de trabalho excedentária em face dos interesses do capital - e os economistas burgueses (que se recusam a admitir que se trata do exército industrial de reserva próprio do tardo-capitalismo) descobrem... o 'desemprego estrutural'! De fato, o chamado "mercado de trabalho" vem sendo radicalmente reestruturado - e todas as "inovações" levam à precarização das condições de vida da massa dos vendedores de força de trabalho: a ordem do capital é hoje, reconhecidamente, a ordem do desemprego e da "informalidade". (PAULO NETTO, 2013, p. 13)

Neste cenário emerge certa flexibilidade e instabilidade do emprego formal, abrindo portas para modalidades de trabalho precarizado, também chamado de “trabalho atípico" por Vasapollo (2005). São assim denominados porque se expressam na forma de prestação de serviços cuja principal característica é a falta ou a insuficiência de tutela contratual. No trabalho atípico, estão inclusas todas as formas de prestadores de serviços diferentes do modelo-padrão com garantias formais e contratuais por tempo indeterminado e full time. 
Essas formas de trabalho "autônomas"10 estão presentes em todo o setor terciário e nas atividades precárias, como acontece nas temporadas dos setores de agricultura, no turismo, nos transportes, entre outros. A diminuição dos postos de trabalho efetivos e estáveis está vinculada a um processo mais amplo de precariedade, que transcende o mercado de trabalho e se impõe como modalidade da vida cotidiana. Também existe uma íntima relação entre flexibilização e precarização, que pode ser tanto salarial, de horário, funcional ou organizativa, mas corresponde a vantagens e possibilidades que beneficiam somente as empresas (ANTUNES, 2011).

Como consequência da instabilidade cotidiana, a ameaça de desemprego confere a empresas o poder de negociação (e/ou imposição) em relação às formas e condições de trabalho, pois, na sociedade capitalista, as negociações entre Capital e Trabalho partem da naturalização do desequilíbrio entre essas duas forças opostas, de forma que mesmo eventuais avanços em direitos não equilibram a balança. Nessa perspectiva, observa-se uma tendência no crescimento dos desafios que testam a capacidade de o trabalhador se manter em condição de vender seu conhecimento, uma vez que esse novo padrão lhe exige qualidade, flexibilidade e maior produtividade para se manter empregável.

A precarização do trabalho é um fenômeno novo e ao mesmo tempo velho, que ocorre de diferentes formas e modalidades. Druck retoma a "tipologia da precarização" elaborada por Franco e Druck (2009, apud DRUCK, 2011, p. 47), composta por cinco tipos de precarização: “vulnerabilidade das formas de inserção e desigualdades sociais"; "intensificação do trabalho e terceirização"; "insegurança e saúde no trabalho"; "fragilização da organização dos trabalhadores" e acrescenta um sexto tipo: a "condenação e o descarte do direito do trabalho".

O primeiro tipo de precarização, denominado "vulnerabilidade das formas de inserção e desigualdades sociais", considerou o total de Pessoas Economicamente Ativas (PEA) fora do mercado de trabalho, os ocupados com remuneração monetária sem

\footnotetext{
${ }^{10}$ Para o Direito brasileiro, essas formas com menos tutelas contratuais não são, por si só, autônomas. Trabalho autônomo é o que é feito sem subordinação, ainda que de forma habitual, mediante contraprestação financeira.
} 
carteira assinada, ou seja, aqueles sem os direitos trabalhistas garantidos pelo emprego formal, e as pessoas com rendimento mensal de menos de um salário mínimo.

O segundo tipo é a "intensificação do trabalho e a terceirização" induzidas pelos padrões de gestão e organização do trabalho com formas de organizar e gerir metas inalcançáveis, ampliação da jornada de trabalho, acúmulo de funções respaldado na gestão por medo, aumento da discriminação e do abuso de poder, incluindo assédio moral.

O terceiro baseia-se na "insegurança e saúde no trabalho" e também se faz presente em nome de maior lucratividade. Segundo Druck (2013), as estatísticas sobre os acidentes de trabalho no país, embora sub-registradas, mostram um aumento de $126 \%$ na quantidade de acidentes entre os anos de 2001 e 2009. Os índices mostram que a taxa de mortalidade por acidente de trabalho é maior entre os empregados terceirizados quando comparada com a de empregados diretos. Ainda com relação à saúde do trabalhador, estudos apontam para o crescimento de questões de saúde mental, que envolvem outro tipo de precarização, denominada "perda da identidade individual e coletiva", resultante da desvalorização simbólica e real e da subjugação à "ditadura do sucesso" como se o indivíduo fosse o único responsável pela sua empregabilidade nas condições adversas naturalizadas do capitalismo flexível (ALVES, 2011).

O quarto tipo resulta da precarização em função da "fragilização da organização dos trabalhadores". Como na esfera sindical, decorre, sobretudo, do acirramento da concorrência entre os trabalhadores, que leva à heterogeneidade e à divisão entre eles, acarretando, nas palavras de Druck (2013, p. 23), em uma "pulverização dos sindicatos criada, principalmente, pela terceirização". Por fim, a autora chama a atenção para "a condenação e o descarte do Direito do Trabalho" através das modificações que ocorreram na Consolidação das Leis do Trabalho (CLT) em 1990.

O atual discurso, por sua vez, prega "uma reforma trabalhista moderna", que atenda às "mudanças no mundo do trabalho", cujos representantes são os "setores mais modernos da indústria brasileira", como o empresariado industrial, representado pela Confederação Nacional das Indústrias (CNI), bem como "alguns dos mais fortes 
sindicatos brasileiros" que participaram ativamente da contrarreforma ${ }^{11}$ trabalhista quando direitos formais foram reduzidos para dar lugar a relações exploradoras com abertura de novos caminhos para ampliação das desigualdades sociais.

As formas de trabalho parcial, temporário, intermitente, terceirizado, sem garantias e direitos caracterizam a superexploração e reforçam o retrocesso social das novas formas de trabalho requeridas pela burguesia que, desde 1970, imprimem os preceitos da acumulação flexível na formação da classe trabalhadora conformando-os à polivalência e à intensificação do trabalho orientados pelo Fundo Monetário Internacional (FMI), Banco Mundial (BM) e por outras instituições financeiras com a anuência do Estado brasileiro, cuja identidade e funcionalidade é atravessada pelo Capital (MÉSZÁROS, 2015).

Após 2008, em meio a crise cíclica do capital, Michel Temer realoca com celeridade a proposta de contrarreforma trabalhista na pauta governamental, angariando os votos necessários para sua aprovação em 11 de julho e promulgação no dia 13 do mesmo mês. Da proposta inicial do PLC n. 38/2017, em 23 de dezembro de 2016, à aprovação pelo Supremo Tribunal Federal, transcorreram apenas sete meses e meio e, em menos de um ano, a lei já estava valendo. Cabe aqui também registrar que essas pautas jamais foram abortadas pelos governos Lula e Dilma.

O referido PLC, na sua matriz original, propunha-se alterar cerca de 100 artigos da Consolidação das Leis do Trabalho (CLT) e mais de 200 dispositivos legais que regulam as relações trabalhistas. Antes de sua aprovação, já era visto como “[...] um instrumento de redução [...] da proteção trabalhista, que, se aprovado causará um abalo sísmico sobre os alicerces do direito do trabalho" (ASSOCIAÇÃO NACIONAL DOS PROCURADORES DO TRABALHO et al, 2017, p. 3).

\footnotetext{
${ }^{11}$ Usa-se a palavra contrarreforma, para significar restrição de direitos, "[...] a palavra reforma foi sempre organicamente ligada às lutas dos subalternos para transformar a sociedade e, por conseguinte, assumiu na linguagem política uma conotação claramente progressista e até mesmo de esquerda. $O$ neoliberalismo busca utilizar a seu favor a aura da simpatia que envolve a ideia de 'reforma' [...]". Desta maneira, estamos diante da tentativa de modificar o significado da palavra 'reforma': o que antes da onda neoliberal queria dizer ampliação dos direitos, proteção social, controle e limitação do mercado etc., significa agora cortes, restrições, supressão desses direitos e desse controle. Estamos diante de uma operação de mistificação ideológica que, infelizmente, tem sido em grande medida bem-sucedida (COUTINHO, 2010, p. 35, grifo do autor).
} 
De acordo com Silva e Jesus (2017), os argumentos que balizaram a contrarreforma são basicamente três: O primeiro são as alegações de altos custos do trabalho, utilizado para justificar a redução dos direitos pela precarização do trabalho e, de ricochete, reduzir os custos da produção, forçando as renúncias fiscais em favor das empresas e reduzindo a participação do capital no custeio da seguridade social e, consequente ampliação da contribuição dos trabalhadores. De acordo com a Associação Nacional dos Auditores-Fiscais da Receita Federal do Brasil (ANFIP) e Fundação ANFIP de Estudos da Seguridade Social e Tributário (2016, p. 22), “[...] em 2015 o conjunto das renúncias [tributárias] totalizou R\$267,3 bilhões".

O segundo motivo funda-se na ideia de crise e no envelhecimento populacional, criando a imagem de um suposto déficit na previdência social quando de fato não existe um orçamento exclusivo da previdência, mas, um orçamento tríplice da seguridade social composto pela Previdência, Assistência e Saúde, o qual, apesar das renúncias tributárias, dos desvios de recursos para outros fins, tem sido superavitário (FATORELLI; ÁVILA, 2017).

O terceiro argumento, utilizado para favorecer a contrarreforma previdenciária e trabalhista, é que os investimentos na previdência pública e outras políticas sociais provocam o aumento da dívida pública dos governos e desequilibram os orçamentos. Porém, se contrastarmos os dados de 2016, formulados pela equipe da auditoria cidadã da dívida, verificaremos que $43,94 \%$ do orçamento foram destinados para os juros e amortizações da dívida pública e apenas 22,54\% à previdência social (AUDITORIA CIDADÃ DA DÍVIDA, 2017).

Esses falaciosos argumentos, repetidos diariamente centenas de vezes pela mídia burguesa, escamoteiam os verdadeiros interesses rentistas que estão por detrás da contrarreforma trabalhista e previdenciária. As pressões do capital financeiro operam nesse esquema corrupto para reduzir os investimentos em políticas públicas e destinar maior parte do fundo público para os serviços da dívida da qual algumas instituições constitutivas do capital financeiro são credoras, além de reduzir o espaço da previdência pública e ampliar o espaço da previdência privada (SILVA; JESUS, 2017). 


\section{Percurso metodológico: dois etnógrafos à margem}

Tendo por base a perspectiva etnográfica defendida por (OLIVEIRA, 2013; REIS; LUNARDI-MENDES, 2018; ROSISTOLATO; PRADO, 2015), tentamos contatar todos os jovens que se formaram nos cursos técnicos de Gastronomia, Panificação e Confeitaria no período entre 2012 e 2013. Era nosso interesse compreender como se deu a inserção profissional desses egressos.

As intensas transformações oriundas do capitalismo global contemporâneo nos exigem questionar o que nos é apresentado como verdade, por isso, buscamos na geografia clássica o conceito de à margem para sistematizar o caminho percorrido pelos etnógrafos. No período em que estávamos elaborando o projeto que resultou nesta pesquisa, tínhamos nítida clareza de que seria muito difícil chegar nesses jovens formados há mais de três anos. Mais difícil ainda, seria convencê-los a conversar com nossa equipe de pesquisa e, permitir que um dos pesquisadores acompanhasse sua rotina diária.

A primeira tentativa de contato com os 24 egressos sujeitos desta pesquisa foi via telefone; informávamos que estávamos fazendo uma pesquisa com jovens, e que era nosso interesse compreender como se deu sua inserção profissional. Questionávamos se o sujeito estava disposto a uma conversa para que pudéssemos detalhar a proposta da pesquisa. Em todas as conversas efetuadas por telefone, nos colocávamos a disposição para ir até sua residência, trabalho ou local em que a pessoa pudesse nos receber.

Com relação aos seis jovens egressos com os quais não conseguimos contato por telefone, fomos até o endereço informado no ato da matrícula. Ao conversar com vizinhos, parentes e/ou pessoas que estavam morando na residência, fomos informados que o jovem tinha migrado para outra região do país.

Além do olhar etnográfico, como procedimento de coleta de dados, aplicamos uma entrevista semiestruturada (MINAYO, 2014) com os dezesseis sujeitos que aceitaram participar do estudo, compartilhando seus dilemas e estratégias para adentrar ao mundo do trabalho. A escolha pela entrevista justifica-se na flexibilidade que o protocolo permite ao pesquisador para absorver temas e reflexões trazidas à tona pelos entrevistados. Após a transcrição, as narrativas juvenis foram analisadas à luz da técnica de Análise de 
Conteúdo (BARDIN, 2011). De acordo com esse procedimento metodológico, a análise textual é feita em três etapas: 1) pré-análise; 2) exploração de material; 3) tratamento dos resultados, com inferência e interpretação à luz do marco conceitual.

Iniciamos a pré-análise com a leitura flutuante dos dados brutos da coleta. Posteriormente, analisamos as respostas dos entrevistados levando em consideração os objetivos da proposta de pesquisa. Em um terceiro momento, com a ajuda do software Atlas.TI, foram analisadas as narrativas em comum nas entrevistas que poderiam ser utilizadas como indicadores na fase de exploração.

A fase de exploração do material coletado também foi efetuada com o auxílio do software Atlas.TI. De acordo com Bardin (2011), essa fase consiste nas operações de codificação e categorização do material coletado. A codificação seria a organização das narrativas em temas. Já a categorização é a classificação dos temas por semelhança ou diferenciação, o que resultou nas categorias de análise desta pesquisa: empreendedorismo, uberização, moradia e despolitização.

\section{Os jovens trabalhadores da 'Ilha da Magia', sujeitos desta pesquisa}

Do total de entrevistados, dez são do sexo feminino e seis são do sexo masculino. Especificamente no grupo analisado, a pesquisa identificou que as mulheres têm mais dificuldade de inserção no trabalho formal, embora sejam mais qualificadas do que os homens. Ao analisar todas as narrativas juvenis, três categorias de análise emergiram com muita força: empreendedorismo, uberização e moradia.

Todos os sujeitos desta pesquisa que já trabalharam na área de conclusão da formação técnica consideram que o trabalho é/era exaustivo, perigoso e insalubre. No que se refere à remuneração, destacam ser incompatível com o grau de responsabilidade que tinham à frente de uma cozinha industrial, padaria ou restaurante.

Essa é uma das razões do empreendedorismo ter aparecido com tanta ênfase nas narrativas: a maioria sonha em criar e gerenciar o seu próprio negócio, estabelecer a sua própria dinâmica de trabalho. Nas palavras do Egresso E1: 
Tipo, não atrai querer trabalhar formalmente. Eu, por exemplo, busco conhecimento, né! Eu não tô lá apenas trabalhando, quero conhecimento pra minha vida. Então, eu quero ver como é que funciona o negócio, eu quero entender. Por isso estou em dois empregos, eu trabalho, lógico, também por dinheiro, porque eu preciso, não é um salário extraordinário, que eu ganho hoje em dia. Pra você ter noção, além do trabalho no restaurante, trabalho também em um free lance. Neste, eu ganho duzentos e cinquenta reais trabalhando um dia. Olha só, veja bem, às vezes fico pensando, por que eu vou ficar me matando em trabalhar numa cozinha oito horas diárias, mais de doze horas no sábado pra ganhar mil e duzentos reais por mês, se eu tipo, trabalhando quatro dias do mês no free lance, eu ganho mil reais? Então, não convém, sabe? [sic] (DEPOIMENTO, Egresso do Curso Técnico em Gastronomia, 2017)

O Jovem E1, para poder se manter, trabalha em dois empregos. No período noturno, comanda a cozinha de um restaurante da área continental de Florianópolis. Considera o trabalho exaustivo, mas a principal motivação para continuar é o conhecimento, já que, no futuro, pretende empreender seu próprio negócio. Pela manhã cursa o ensino superior em produção de alimentos na $\operatorname{UFSC}^{12}$ e, nas horas vagas, trabalha em um free lance no bairro Ratones ( $50 \mathrm{~km}$ da sua residência). Nos últimos anos passou a residir no município de Biguaçu, diante dos altos preços dos alugueis na 'Ilha da Magia'.

O discurso do empreendedorismo fomenta em muitos trabalhadores o desejo de criar seu próprio negócio, com o intuito de encontrar uma saída para sua situação urgente. Porém, esse discurso homogeneizador, carregado de ideologia neoliberal, os expropria ao criar um cenário de oportunidades falaciosas; ao mesmo tempo, os destitui da sua identidade de trabalhador. Estonteados pela nebulosa "nova identidade de empreendedor", eles acabam por incorporar discursos aburguesados, que operam na contramão dos seus próprios interesses de classe, deteriorando direitos conquistados pela classe trabalhadora ao longo de sua história de lutas.

Esse complexo entrelaçamento de ações pedagógicas, nas duas últimas décadas, vem se caracterizando por conjugar, em proporções particulares: a ênfase na educação como solução individual para a precarização da vida e para o intensificado processo de destituição de direitos; a captura de movimentos (sociais e sindicais) de organização dos

\footnotetext{
${ }^{12}$ Universidade Federal de Santa Catarina.
} 
trabalhadores, visando a torná-los copartícipes de sua própria condição de expropriação e pela conversão mercantil-filantrópica, assim como pelo empresariamento direto de setores populares (FONTES, 2010, p. 347).

Podemos evidenciar, a partir das entrevistas, que as concepções dos egressos revelam as ressonâncias da liberal democracia, materializada nos acordos firmados entre - Estado brasileiro e os organismos multilaterais que prescrevem a própria precarização do trabalho humano, ainda que com palavras adocicadas. Esses documentos norteadores que se incorporaram à Educação Profissional correspondem à própria expectativa do capital, que busca a máxima eliminação do trabalho vivo e, ao mesmo tempo, induz que parte da força de trabalho seja facilmente encaixável nas novas modelagens e engrenagens produtivas que oscilam a cada avanço tecnológico.

A pesquisa também identificou uma alta qualificação para postos ocupados pelos jovens entrevistados. Citamos como exemplo a Egressa E7 do curso técnico em panificação e confeitaria, que gerencia a padaria de um bairro nobre da ilha. Além do curso técnico, a jovem é formada em Secretariado Executivo Bilíngue pela UFSC e possui um MBA em gestão estratégica.

A padaria gerenciada por E7 atende a um público seleto da cidade de Florianópolis. É especializada em produtos veganos, sem glúten e sem lactose. Por isso, nos últimos anos, a entrevistada também vem investindo em cursos de qualificação profissional que abordam as especificidades da alimentação alternativa.

Outro exemplo de hiperqualificação é a jovem E4, egressa também do curso técnico em panificação e confeitaria. Além do curso no IFSC, concluiu também a graduação em administração pública na UDESC ${ }^{13}$. Atualmente desenvolve produtos na área de confeitaria artística para comercialização no leste da ilha.

A estratégia de trabalho desenvolvida por E4 se assemelha um pouco à lógica do aplicativo Uber. De acordo com a narrativa, através de um aplicativo tecnológico, um proprietário do restaurante, por exemplo, pode contratar produtos específicos como: petit gâteau, ostras gratinadas, tortas customizadas. O trabalhador prestador do serviço

\footnotetext{
${ }^{13}$ Universidade do Estado de Santa Catarina.
} 
paga uma taxa mensal para se cadastrar no aplicativo. Para os estabelecimentos - bares, hotéis e restaurantes - torna-se algo vantajoso, pois o empresário desfruta de um serviço de alta qualidade, sem a necessidade de pagar os encargos sociais e trabalhistas. Tais aplicativos tecnológicos não oferecem apenas serviços na área da gastronomia; com apenas um toque no celular, você pode escolher um serviço customizado na área de limpeza, jardinagem, cuidado com idosos, serviços de pet etc.

Ao ser questionada sobre o futuro, E4 afirma que pretende fazer um intercâmbio na Europa para se especializar em tortas customizadas. Pensa que a gastronomia local não tem dado a devida importância para as sobremesas, bem como à harmonização com as bebidas.

Coincidentemente, para chegar até a residência da egressa E4 - leste da ilha utilizamos o serviço de transporte via aplicativo Uber. Em conversa durante o percurso que durou 50 minutos, a motorista explicitou o seu dilema profissional: 47 anos, duas graduações, dois MBA. Tem sido chamada para várias entrevistas de emprego, mas acredita que sua idade tem sido um impeditivo. Para tentar pagar as contas, passou a trabalhar como motorista via aplicativo Uber.

Compartilhou conosco as condições subalternas: a empresa UBER fica com 30\% de todo valor das viagens realizadas, restando para o motorista $70 \%$ do valor arrecadado; deste, é preciso pagar o combustível, a manutenção do carro e o almoço. Enfatizou que às vezes ela precisa fazer um grande deslocamento para pegar o passageiro e esse deslocamento fica por sua conta; se recusar uma viagem não lucrativa que o aplicativo programou, é penalizada com multa. Conforme sintetiza Antunes:

A instabilidade e a insegurança são traços constitutivos dessas novas modalidades de trabalho. Vide a experiência britânica do zero hour contract (contrato zero hora), o novo sonho empresariado global. Tratase de uma espécie de trabalho sem contrato, no qual não há previsibilidade de horas a cumprir nem direitos assegurados. Quando há demanda, basta uma chamada e os trabalhadores e as trabalhadoras devem estar on-line para atender o trabalho intermitente. As corporações se aproveitam: expande-se a 'uberização', florescendo uma nova modalidade de trabalho: o escravo digital. Tudo isso para disfarçar o assalariamento. (Antunes, 2018, p. 23) 
Voltando aos jovens sujeitos desta pesquisa, entre as pessoas que atuam ou já atuaram com carteira assinada, foi possível identificar que há uma grande rotatividade nos empregos. A média de permanência na atividade laboral é de doze meses. Dois fatores contribuem para essa movimentação: comércios que inauguram e, após alguns meses, acabam encerrando suas atividades por conta das dificuldades financeiras. Outro fator que acaba influenciando os jovens a procurarem outras empresas diz respeito às condições precárias e insalubres às quais são submetidos.

O distanciamento dos jovens sobre as discussões acerca do ajuste fiscal e a flexibilização das leis trabalhistas é outra característica marcante dos entrevistados. Expressões como "no grêmio só tem pessoas malucas" [sic] e "cara, não vejo televisão, então não faço ideia do que ocorre no mundo da política", foram recorrentes. A internet se mostrou como a principal fonte de informação dos egressos. Porém, o acesso fica restrito às redes sociais digitais. No grupo analisado, foi possível constatar que, geralmente, os jovens navegam em bolhas, ou seja, interagem através de grupos de discussão hospedados nas redes cibernéticas, sendo que os entrevistados não têm a iniciativa de checar se as informações difundidas são verdadeiras.

Através das entrevistas, podemos confirmar que o projeto neoliberal encampado estrategicamente desde a década de 1990 na Educação Profissional não se compromete com a totalidade dos sujeitos, tampouco com a emancipação da classe trabalhadora. $O$ entendimento burguês sobre o conceito de emancipação lhe insere como um elemento: o de consumidor. Para a democracia liberal burguesa, cidadão é aquele que consome, que define o que vestir, o que comer, o que comprar, enfim, o que participa das "decisões da sociedade" ao definir os rumos do mercado, como se consumir fosse essencialmente um ato de cidadania, blindado das induções externas ao sujeito.

Essa noção equivocada de cidadania também oblitera a possibilidade de participação dos sujeitos nas decisões da polis ao reduzi-lo a mero comprador e restringe a democracia a um modelo censitário-autocrático, que naturaliza a tomada de decisões em função dos níveis de consumo, similar a assembleias de acionistas das empresas, em que a disputa por projetos dá-se pelo poder de barganha dos atores políticos. 
O consumo participativo, ao contrário do discurso hegemônico, não é uma ferramenta de participação popular e torna nebulosos os interesses da classe trabalhadora ao forjar-se com apoio do mais poderoso narcótico social: o consumo. Oliveira (2003) nos aponta que, ainda que todos os produtos da revolução moleculardigital chegassem aos estratos mais baixos da população, isso não significaria a sua emancipação e nem uma vida plena de sentido, pois o consumo, em si, não humaniza.

Conforme apontaram as entrevistas dos egressos, as condições de trabalho da classe trabalhadora brasileira não se alteraram estruturalmente nos últimos anos, ainda que esses sujeitos tenham elevado sua escolaridade e se qualificado profissionalmente. A expansão econômica, a modernização tecnológica, a elevação progressiva da renda ou o acesso ao consumo, fomentado pela liberação do microcrédito, tornam-se visíveis através de símbolos internos do capital, que manipulam e ofuscam a consciência crítica das classes oprimidas. Ganharam adesão das classes médias, manifestando-se na massificação da "condição burguesa" para fora da burguesia que implantou, no coração de seus inimigos de classe, identificações e lealdades mais ou menos profundas para com o consumismo, a ordem social competitiva e o Estado democrático e nacional (FONTES, 2010).

A escolha política da cidadania pelo consumo, colocada em curso pelo governo petista nos últimos 13 anos, encampou uma 'revolução pelo alto"14 e reafirmou a estrutura desigual da sociedade brasileira. Ao conservar os ideais liberais no coração da classe trabalhadora, após um breve respiro de alívio em relação à pobreza, o Brasil mergulha numa profunda depressão, fruto da crise cíclica do capital que não mais possibilita conciliação entre o Trabalho e o Capital da última década. Em meio a essa crise, depois de ter usufruído de pequenas benesses, os trabalhadores brasileiros assistem ao desmonte dos direitos que levaram décadas para serem construídos e seguem no desafio de reorganizar as bases, num cenário dificultado pela própria morfologia difusa da classe e pelo apassivamento que esvaziou as lutas classistas na última década. Se é verdade que

\footnotetext{
${ }^{14}$ Álvaro Bianchi chamou de "revolução pelo alto" o momento em que a "direção intelectual e moral da sociedade brasileira" descola-se das classes subalternas, tendo no comando do aparato de Estado a burocracia sindical do "novo sindicalismo", que reforçou ainda mais a ordem burguesa quando parte "dos de baixo" passou a dirigir o Estado por intermédio do programa "dos de cima" (BRAGA, 2012).
} 
os ganhos mínimos das políticas de gotejamento ${ }^{15}$ geraram otimismo para os trabalhadores que viviam na mais absoluta aridez, também é verdade que esse modelo naufragou no momento em que o Estado precisou reafirmar com quem ele se compromete.

\section{Considerações finais}

A análise das entrevistas com os jovens egressos dos cursos técnicos do eixo turismo, hospitalidade e lazer do IFSC Campus Florianópolis Continente nos demonstra a apropriação do discurso midiático e mercadológico por grande parte desses jovens. Pudemos evidenciar a dificuldade de um compreensão mais ampla e crítica do mundo do trabalho e a ausência de vivências e propostas coletivas como resposta para uma dificuldade que está posta para a jovem força de trabalho florianopolitana que tem buscado na qualificação profissional a solução para seus problemas de classe em solos urbanos.

\section{Referências}

ALVES, Giovanni. Trabalho e subjetividade: o espírito do toyotismo na era do capitalismo manipulatório. São Paulo: Boitempo, 2011.

ANTUNES, Ricardo. O privilégio da servidão: o novo proletariado de serviços na era digital. São Paulo: Boitempo, 2018.

ANTUNES, Ricardo. Século XXI: nova era da precarização estrutural do trabalho? In: ANTUNES, Ricardo; BRAGA, Ruy (Orgs.). Infoproletários: degradação real do trabalho virtual. São Paulo: Boitempo, 2011.

ANTUNES, Ricardo. Desenhando a nova morfologia do trabalho no Brasil. Estudos Avançados, São Paulo, v. 28, n. 81, p. 39-53, mai/ago. 2014. Disponível em:

\footnotetext{
15 Fontes (2010) ressalta que, mesmo diante de todas as críticas, é preciso considerar que há ganhos mínimos para as pessoas pobres no contexto de um país de extrema desigualdade. As políticas de gotejamento, segundo ela, distribuíram gotas de água para regiões muito áridas socialmente e surtem algum efeito, já que é melhor ter gota d'água do que não ter água nenhuma. Do ponto de vista da redução da miséria absoluta, elas atingem alguma coisa, mas não alteram as condições da desigualdade e continuarão sem alterar, pois essas pequenas mudanças não significam garantia de direitos e muito menos se comprometem com a produção qualificada de trabalho socializado.
} 
http://www.scielo.br/scielo.php?pid=S0103-40142014000200004\&script=sci_arttext. Acesso em: 28 fev. 2018.

ASSOCIAÇÃO NACIONAL DOS AUDITORES-FISCAIS DA RECEITA FEDERAL DO BRASIL; FUNDAÇÃO ANFIP DE ESTUDOS DA SEGURIDADE SOCIAL E TRIBUTÁRIO. Análise da Seguridade social 2015.16. ed. Brasília, DF, jul.2016.

ASSOCIAÇÃO NACIONAL DOS PROCURADORES DO TRABALHO et al. Nota Técnica conjunta PLC 38/2017 - Reforma Trabalhista. Brasília, DF, 2017. Disponível em: file://D:/USER/Desktop/valdeci/Nota\%20T\%C3\%A9cnica\%20Conjunta\%20\%20Reforma\%20Trabalhista.pdf. Acesso em: 19 jun. 2017.

BARBOSA, Frederico Cavadas. Mercado de trabalho de migrantes nordestinos: os empregados de edifício no Rio de Janeiro. In: ENCONTRO NACIONAL DE ESTUDOS POPULACIONAIS, 13. Anais... Rio de Janeiro, ENEP, 2000.

BARDIN, Laurence. Análise de Conteúdo. São Paulo: Edições 70, 2011.

Beck, Anamaria. Lavradores e pescadores - um estudo sobre trabalho familiar e trabalho acessório. Florianópolis, UFSC, Trabalho apresentado ao Concurso de Professor Titular, 1979.

Beck, Anamaria. "Trabalho limpo: a renda-de-bilro e a reprodução familiar". Cadernos Anhatomirim, 4, Florianópolis, UFSC, 1983.

BOURDIEU, Pierre. A reprodução. Rio de Janeiro: Francisco Alves, 1992.

BORELLI, Silvia; ROCHA, Rose de Melo; OLIVEIRA, Rita de Cássia Alves. Jovens na cena metropolitana: percepções, narrativas e modos de comunicação. São Paulo: Paulinas, 2013.

BRAGA, Ruy. A angústia dos subalternos. In: BRAGA, Ruy. A política do precariado: do populismo à hegemonia lulista. São Paulo: Boitempo, 2012, p. 181-222.

BRASIL. Lei n. 12.852, de 5 de agosto de 2013. Institui o Estatuto da Juventude e dispõe sobre os direitos dos jovens, os princípios e diretrizes das políticas públicas de juventude e o Sistema Nacional de Juventude - SINAJUVE. Casa Civil, Brasília, DF. Disponível em: http://www.planalto.gov.br/ccivil_03/_Ato2011-2014/2013/Lei/L12852.htm. Acesso em: 14 mar. 2018. 
BRASIL. Lei 10.257, de 10 de julho de 2001. Regulamenta os arts. 182 e 183 da Constituição Federal, estabelece diretrizes gerais da política urbana e dá outras providências. Casa Civil, Brasília, DF. Disponível em:

http://www.planalto.gov.br/ccivil_03/leis/leis_2001/l10257.htm. Acesso em: 02 mar. 2018.

CARRANO, Paulo. Jovens, escolas e cidades: Desafios à autonomia e à convivência.

Revista Teias, Rio de Janeiro, v. 12, n. 26, p. 07-22, set./dez. 2011.

CARUSO, Mariléia Martins Leal. O desmatamento da ilha de Santa Catarina. Florianópolis: EDUFSC, 2012.

COUTINHO, Carlos Nelson A hegemonia da pequena política. In: OLIVEIRA, Francisco de; BRAGA, Ruy; RIZEC, Cibele Saliba. (Orgs). Hegemonia às avessas: economia, política, na era da servidão financeira. São Paulo: Boitempo, 2010. p. 29-43.

DAYRELL, Juarez. A escola faz juventudes? Reflexões sobre a socialização juvenil. Revista Educação \& Sociedade, Campinas, v. 28, n. 100, p. 1105-1111, out. 2007.

DAYRELL, Juarez. Juventud, grupos culturales y sociabilidad. Jovenes: Revista de Estudios sobre Juventud, México, n. 22, p. 128-147, 2005.

DAYRELL, Juarez. Cultura e identidades juveniles. Ultima década. Vina Del Mar, Chile, n. 18, p. 69-92, abr. 2003.

DRUCK, Graça. Trabalho, precarização e resistências: novos e velhos desafios? Caderno CRH, Salvador, v. 24, p. 37-57, 2011.

DRUCK, Graça. A legalização da “precarização”, da flexibilização e da modernização do trabalho no Brasil: as 101 propostas da Confederação Nacional das Indústrias (CNI). In:

Anais do XIX Congresso da Associação Latino Americana de Sociologia, 29, 2013, Santiago.

FATORELLI, M. L.; ÁVILA, R. Auditoria Cidadã da Dívida. Disponível em: https://auditoriacidada.org.br/. Acesso em: 28 de jun. de 2017.

FONTES, Virginia Maria. O Brasil e o capital-imperialismo: teoria e história. Rio de Janeiro: FIOCRUZ/UFRJ Editora, 2010.

FRIGOTTO, Gaudêncio; CIAVATTA, Maria e RAMOS, Marise. A Política de educação profissional no governo Lula: um percurso histórico controvertido. Educ. Soc., Campinas, v. 26, n. 92, p. 1087-1113, 2005.

KUENZER, Acacia Zeneida. As políticas de educação profissional: uma reflexão necessária. In: MOLL, Jaqueline. (Org.). Educação profissional e tecnológica no Brasil contemporâneo: desafios, tensões e possibilidades. Porto Alegre: Artmed, 2010. 
LINS, Hoyêdo Nunes. Herança açoriana e turismo na Ilha de Santa Catarina. Revista de Ciências Humanas, Florianópolis: UFSC, p. 89-117, 1993.

MÉSZÁROS, I. A montanha que devemos conquistar: reflexões acerca do Estado. São Paulo: Boitempo Editorial, 2015.

MINAYO, Maria Cecília de Souza. O desafio do conhecimento: pesquisa qualitativa em saúde. 14.ed. São Paulo: Hucitec, 2014.

PAULO NETTO, José. “Uma face contemporânea da barbárie”. Novos Rumos, Marília, v. 50, n. 01, p. 1-39, 2013.

OLIVEIRA, Amurabi. Por que etnografia no sentido estrito e não estudos do tipo etnográfico em educação? Revista FAEEBA, Salvador, v. 22, n. 40, p. 69-82, 2013.

OLIVEIRA, Francisco de. Crítica à razão dualista; o ornitorrinco. São Paulo: Boitempo, 2003.

PEREIRA, Elson Manoel. Como anda a participação? As condições para a elaboração de planos diretores participativos. Revista Brasileira de Estudos Urbanos e Regionais, Recife/PE, v. 19, n. 2, p. 235, abr. 2017. Disponível em:

http://rbeur.anpur.org.br/rbeur/article/view/5380. Acesso em: 02 mar. 2018.

PEREIRA, Elson Manoel. A alegoria da participação: planos diretores participativos pósestatuto da cidade. Florianópolis: Insular, 2015.

RANZOLIN, Ivan. Ata da Assembleia Legislativa do Estado de Santa Catarina.

Florianópolis, 11 de nov. de 1993.

REIS, Valdeci. Jovens professores conectados: os desafios da docência na era digital. 2016. 177f. Dissertação (Mestrado em Educação) - Centro de Ciências Humanas e da Educação, Universidade do Estado de Santa Catarina, Florianópolis, 2016.

REIS, Valdeci; GELSLEICHTER, Meimilany; ALVES, Emilaura. Narrativas juvenis: dilemas, tensões e desafios em torno das novas configurações do mundo do trabalho. Educação e Emancipação, São Luís, v. 10, n. 3, p. 41-63, set/dez. 2017.

REIS, Valdeci; LUNARDI-MENDES, Geovana Mendonça. O registro do etnógrafo: reflexões sobre a prática etnográfica educacional. Revista Contemporânea de Educação, Rio de Janeiro, v. 13, n. 26, p. 164-183, 2018.

ROSISTOLATO, Rodrigo; PRADO, Ana Pires. Etnografia em pesquisas educacionais: o treinamento do olhar. Linhas Críticas, v. 21, p. 57-75, 2015. 
RUMMERT, Sonia Maria; ALGEBAILE, Eveline; VENTURA, Jaqueline. Educação da classe trabalhadora brasileira: expressão do desenvolvimento desigual e combinado. Revista Brasileira de Educação, Rio de Janeiro, v. 18 n. 54 jul-set, p.717-738, 2013.

SAMPAIO, Juliana Búrigo. Disputas territoriais e processo participativo em Florianópolis. 2016. Dissertação (Mestrado em Geografia) - Centro de Filosofia e Ciências Humanas, Universidade Federal de Santa Catarina, Florianópolis, 2016.

SCHULTZ, Theodore William. O valor econômico da educação. Rio de Janeiro: Zahar, 1967. $101 \mathrm{p}$.

SILVA, Maria Lucia Lopes da; JESUS, Júlio César Lopes de. Contrarreforma trabalhista e previdenciária: implicações para os trabalhadores. Revista de Políticas Públicas, São Luís, v.21, n.2, jul-dez, p.577-602, 2017. Disponível em:

http://www.periodicoseletronicos.ufma.br/index.php/rppublica/article/view/8235/5072. Acesso em: 19 de jul. de 2018.

VASAPOLLO, Luciano. 0 trabalho atípico e a precariedade. São Paulo: Expressão Popular, 2005.

Recebido em: 22/03/2018 Aprovado em: 03/08/2018

Universidade do Estado de Santa Catarina - UDESC Centro de Ciências Humanas e da Educação - FAED

Revista PerCursos

Volume 20 - Número 42 - Ano 2019 revistapercursos@gmail.com 